\title{
Nutrition of patients with severe neurologic impairment
}

\author{
Anija Orel ${ }^{1,3}$, Matjaz Homan ${ }^{1,2,3}$, Rok Blagus ${ }^{4}$, Evgen Benedik ${ }^{1,3}$, Rok Orel ${ }^{1,2,3}$, Natasa Fidler Mis ${ }^{1,3}$ \\ 1 University Medical Centre Ljubljana, Children's Hospital, Ljubljana, Slovenia \\ 2 University of Ljubljana, Faculty of Medicine, Chair of Paediatrics, Ljubljana, Slovenia \\ ${ }^{3}$ University of Ljubljana, Biotechnical Faculty, Department of Food Science and Nutrition, Ljubljana, Slovenia \\ ${ }^{4}$ University of Ljubljana, Faculty of Medicine, Institute for Biostatistics and Medical Informatics, Ljubljana, Slovenia
}

Radiol Oncol 2018; 52(1): 83-89.

Received 8 September 2017

Accepted 15 October 2017

Correspondence to: Prof. Rok Orel, M.D., Ph.D., University Medical Centre Ljubljana, Children's Hospital, Department of Gastroenterology, Hepatology and Nutrition, Bohoričeva 20, SI-1525 Ljubljana, Slovenia. E-mail: rok.orel@kclj.si

Disclosure: No conflicts of interest were disclosed.

Background. Commercial enteral formulas are generally recommended for gastrostomy feeding in patients with severe neurologic impairment. However, pureed food diets are still widely used and even gaining popularity among certain groups. We tried to compare the effectiveness of gastrostomy feeding for treatment of severe malnutrition with either enteral formulas or pureed feeds.

Patients and methods. A 6-month nutritional intervention was made with 37 malnourished children, adolescents and young adults (2-26 years old) with severe neurologic impairment (Gross Motor Function Classification system [GMFCS] grade V). The individual needs were calculated. Participants were fed by gastrostomy with either enteral formulas $(n=17)$ or pureed food $(n=20)$. Measurements to assess nutritional status were made at the beginning and at the end of intervention.

Results. The $\mathrm{Z}$ scores for weight-for-age and for the body-mass index increased more in enteral formula than in pureed food group ( 2.07 vs. $0.70, p=0.0012$; and 3.75 vs. $0.63, p=0.0014$, respectively). Fat mass index increased more in enteral formula than in pureed food group $\left(1.12 \mathrm{~kg} / \mathrm{m}^{2} \mathrm{vs} .0 .38 \mathrm{~kg} / \mathrm{m}^{2} ; \mathrm{p}=0.0012\right)$. Patients in the enteral formula group showed increase in lean body mass expressed as fat-free mass index $\left(0.70 \mathrm{~kg} / \mathrm{m}^{2}\right)$, while those in pureed food group did not $\left(-0.06 \mathrm{~kg} / \mathrm{m}^{2}\right)(\mathrm{p}=0.0487)$.

Conclusions. The results suggest that even professionally planned pureed food diet is less effective than commercial enteral formula for nutritional rehabilitation of malnourished patients with severe neurologic impairment. However, larger and if possible randomised clinical studies should be made to confirm our findings.

Key words: malnutrition; severe neurologic impairment; gastrostomy; enteral formula; pureed food

\section{Introduction}

Patients with neurologic impairment often suffer from feeding difficulties and limitations. Severity of feeding problems usually correlates with functional degree of neurologic impairment. Dysphagia and frequent food aspirations, gastroesophageal reflux, dysmotility of gastrointestinal tract, slow gastric emptying and digestion very often appear in patients with severe impairment. ${ }^{1-5}$ Consequently, malnutrition is common problem in this group of patients. According to published studies, at least
$40 \%$ of patients with severe neurologic impairment are malnourished, however, some studies estimated that the rate of malnourished patients is even above $90 \%{ }^{4,6-8}$ Therefore, it is essential that malnutrition in these patients is recognized as soon as possible and appropriately treated to prevent the risk of bad outcomes. ${ }^{6}$

Built and body composition as well as energy and nutritional needs of these patients are importantly altered by the nature of their illness, so there is no consistent recommendation for the assessment of their nutritional status. ${ }^{8,9}$ To prevent 
or/and treat malnutrition, it is very important to estimate energy needs and adequacy of energy and nutrient intake. In case there is suspicion that patient has feeding difficulties, they should be reviewed and evaluated by team of experts. ${ }^{10,11}$ If mild feeding problems are recognized, rehabilitation therapy and teaching of right feeding techniques by experts is recommended. ${ }^{12,13}$ In patients with swallowing problems, liquid or pureed foods can be used. In patients with chocking problems during eating liquid foods, thickening agents can be added. When appropriate nutritional intake is not achieved by natural food, medium chain fatty acids (MCT oil), sugar polymers or hypercaloric enteral formulas can be added to increase energy density of food. ${ }^{11}$

In patients with severe feeding problems, that cannot eat sufficient amount of food through mouth, placement of feeding gastrostomy tube is necessary. ${ }^{14}$ Additional indications for gastrostomy feeding are frequent aspirations during feeding and an excessive amount of time spent to feed the patient during the day. Numerous studies demonstrated important improvements in nutritional status of patients with severe neurologic impairment after the placement of gastrostomy tube..$^{15-19}$

Enteral formulas with all macro and micro nutrients that suffice for long term exclusive use are recommended for gastrostomy feeding of neurologic patients ${ }^{19}$, but pureed food diets are still very popular and widely used by parents due to beliefs such food is more natural and healthy. ${ }^{20}$ Several researches studying composition of pureed gastrostomy feedings prepared at home or at hospital showed that they were less reliable in providing energy and nutrients, and could be contaminated by pathogenic microorganisms. ${ }^{21-23}$ On the other hand, recent cross-sectional study of tube-fed adult patients receiving home enteral nutrition revealed that over $50 \%$ of patients were consuming homemade pureed food occasionally or regularly, despite they had been prescribed commercially available formulas..$^{24}$ Moreover, $46 \%$ of the patients reported that pureed food comprised more than $50 \%$ of their daily enteral feedings, most of them using their own recipes or recipes obtained from the internet. In the aforementioned study, patients reported fewer overall symptoms while using pureed feeds compared with a commercial enteral formula. A recently published review concerning special issues in tube-fed children found very little evidence regarding the appropriateness of home-prepared pureed food for gastrostomy feeding in children. It was emphasized that patients on pureed food should be under the supervision of health professionals, who could ensure that the diet was providing the proper nutrients profile. In addition, they pointed out that controlled trials were needed to evaluate the effectiveness of pureed tube feedings. ${ }^{25}$

In the face of these facts, whether pureed food accurately planned by skilled clinical dietitian, who takes into account all a patient's need for energy, macro- and micronutrients, ensures adequate nutritional support for patients with severe neurological impairment, appears an important issue. We therefore performed a prospective study to compare the effect of two different types of gastrostomy feeding, either enteral formula or pureed food, on the nutritional status of severely undernourished neurologically impaired children, adolescents and young adults.

\section{Patients and methods}

This study was conducted as a part of a $\mathrm{PhD}$ research project. It was a study made on young patients with severe neurologic impairment and feeding difficulties that were identified as moderately or severely malnourished in the outpatient Clinic for Enteral Nutrition of the University Children's Hospital Ljubljana, Slovenia, between the years 2013 and 2016. Patients received intervention during a 6-month period.

Forty-five young patients aged between 2 and 26 years with severe neurologic impairment (Gross Motor Function Classification system [GMFCS] grade $\mathrm{V}$ ) were identified with moderate or severe malnutrition and included in the study. Their nutritional status was evaluated by Z scores of weightfor-age, with definition of moderate malnutrition as $\mathrm{Z}$ score below -2 and severe malnutrition with $\mathrm{Z}$ score below -3 according to WHO standards. ${ }^{26}$ All included patients were fed by gastrostomy with at least of $80 \%$ of their food daily intake. Patients with progressive neurologic diseases or genetic syndromes were excluded. We also excluded patients that require special diets, such as ketogenic diet. Protocol of the study was approved by the Slovenian National Committee for Medical Ethics (KME n. 170/05/14), and written consent was obtained from parents/legal guardians.

\section{Nutritional intervention}

We calculated energy and macronutrient requirements for all included patients with D-A-CH refer- 
ence values for typically developing children. ${ }^{27} \mathrm{We}$ used energy needs per body weight for children, adolescents or adults of the same age with addition of $30 \%$ for catch up' growth of severely malnourished patients. ${ }^{28}$ Target energy intake was achieved within 2 weeks, with gradual increase from 100 to $130 \%$ of recommended daily energy intake to prevent the risk of refeeding syndrome.

Patients were divided into 2 groups, the first receiving exclusively enteral formula and the second receiving carefully planned pureed food diet with maximum of $20 \%$ of energy intake provided by food supplements or formula, when it was necessary to meet their requirements. As majority of parents/caregivers did not agree with randomisation, but demanded that their child was included in one or another group, the study was performed as open labelled comparative interventional study. Diet plans for pureed food group were carefully prepared by the team of clinical dietitians to meet requirements for energy, macro and micronutrient intake. An intake of about $2 \mathrm{~g}$ of protein per $\mathrm{kg}$ of body weight was used to cover increased needs during nutritional rehabilitation. ${ }^{28}$ For the formulafed group we used relatively high-energy density formula $(1.5 \mathrm{kcal} / \mathrm{ml})$ with added fibre, as majority of the patients were having poor tolerance for feeding volumes. Patients under the age of 12 years were fed with NutriniDrink Multi Fibre, while patients over the age of 12 with NutriDrink Multi Fibre (manufactered by Nutricia, Netherlands). The daily intake of enteral formula was determined based on previously calculated energy requirements. Parents/caregivers of both groups received personal nutritional counselling and instruction from the clinical dietitian.

\section{Nutritional status assessment}

We measured body weight with an electronic scale (Seca, Germany), length of ulna with sliding calliper (Holtain, UK), and skinfold thicknesses with skinfold calliper (Harpenden, UK) on patients' left-hand side or less affected side (in case of asymmetrical impairment) at the time of inclusion and again after 6 months of intervention.

Patients' body height was estimated with the equations using ulna length from Gauld et al. ${ }^{29}$

$$
\begin{array}{ll}
H=4.605 U+1.308 A+28.003 & \text { for boys } \\
H=4.459 U+1.315 A+31.485 & \text { for girls }
\end{array}
$$

where $\mathrm{H}$ is height $(\mathrm{cm}), \mathrm{A}$ is age (years), and $\mathrm{U}$ is ulna length $(\mathrm{cm})$.
Body weight and estimated body height were used to obtain Z-scores for weight-for-age, heightfor-age and BMI-for-age by using calculator based on 2006 WHO child growth standards. ${ }^{26}$ Detected $\mathrm{Z}$ scores were used for the estimation of nutritional status before and after intervention, because we wanted to assess differences in the grade of nutrition according to normal population considering age, sex as well as starting grade of malnutrition.

Percentage of body fat was calculated from skinfold thickness data by using Slaughter's equations ${ }^{30}$ modified by Gurka et al. for patients with cerebral palsy. ${ }^{31}$ We calculated body fat mass (FM) and lean body mass (fat free mass) (LM) from percentage of body fat and body weight. Fat mass and lean body mass were then normalised for height $(\mathrm{H})$ by calculating fat mass index (FMI) and fat-free mass index (FFMI) (both in $\mathrm{kg} / \mathrm{m}^{2}$ ):

$$
\begin{aligned}
& \mathrm{FMI}=\mathrm{FM} / \mathrm{H}^{2} \\
& \mathrm{FFMI}=\mathrm{FFM} / \mathrm{H}^{2}
\end{aligned}
$$

\section{Statistical methods}

The differences between the pureed food group and enteral formula group at baseline were tested with t-test, Welch t-test or Mann-Whitney test as appropriate for the continuous variables (the normality assumption and the assumption of homoscedasticity, i.e. equal variances, were verified with the Shapiro-Wilk test and Bartlett test, respectively) and Chi-square test or Fisher exact test for categorical variables.

The differences between the groups in time were tested with linear mixed effects models including subject as a random effect using maximum likelihood method for parameter estimation. Group and time interaction was included in all the models, and its significance was verified with the likelihood ratio test. Contrast analysis was used to explore the interaction effect; note that since the contrasts were not orthogonal the p-values were adjusted with Holm's method to appropriately control the type I error.

A p-value of less than 0.05 was considered as statistically significant. The analysis was performed with $\mathrm{R}$ language for statistical computing ( $R$ version 3.0.0). ${ }^{32}$

\section{Results}

From the 45 included patients, 37 have completed the 6-month interventional study. In four cases 


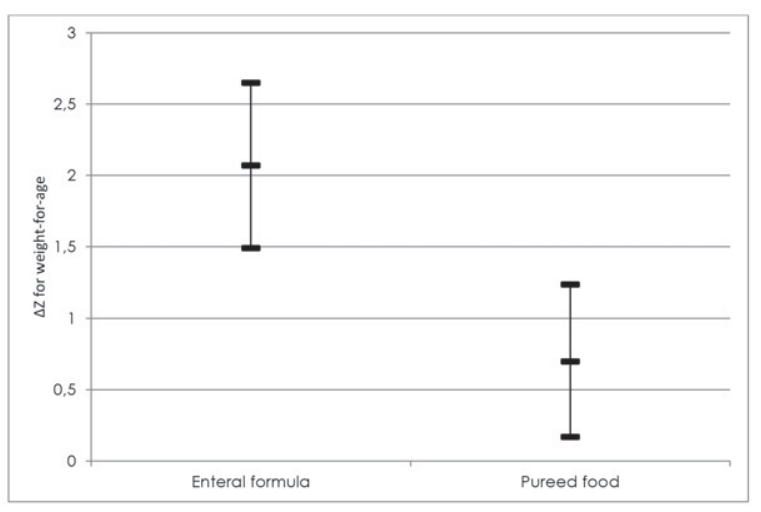

FIGURE 1. Changes of $Z$ scores for weight-for-age after 6-month nutritional intervention expressed as mean values with $95 \%$ confidence interval.

parents didn't follow the instructions and switched the feeding regime (three from formula and one from pureed group), three decided to abandon the regime due to personal reasons and one of the patients died few months after the inclusion. There were 17 patients in enteral formula and 20 in pureed food group who completed the interventional study.

As the patients in enteral formula were significantly older ( $13.7 \pm 4.7$ years $v s .9 .4 \pm 6.6$ years), we applied multivariate models that adjusted to age difference.

\section{Weight gain and growth}

Patients in both groups improved in their weightfor-age $\mathrm{Z}$ scores significantly, in enteral formula group for 2.07 (95\% CI: $1.49-2.65, \mathrm{p}=0.0000)$ and in pureed food group for 0.7 (95\% CI: $0.17-1.24$, $\mathrm{p}=$ 0.0114 ) as shown in Figure 1. Both groups also im-

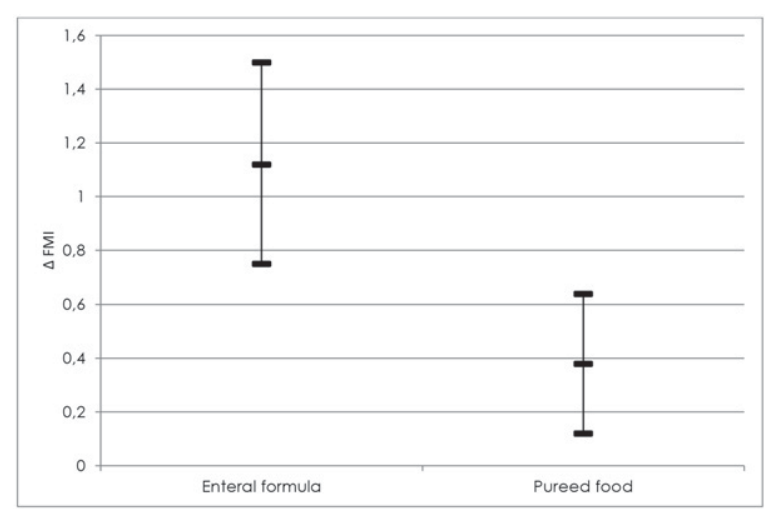

FIGURE 3. Changes in fat mass indexes (FMI) after 6-month nutritional intervention expressed as mean values with $95 \%$ confidence interval.

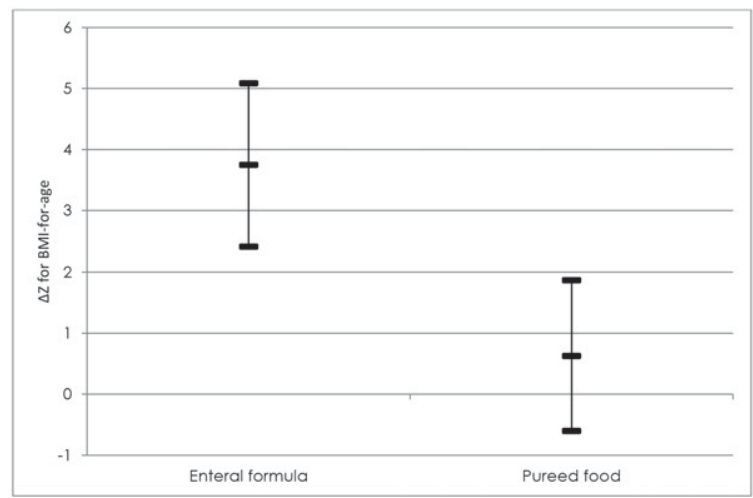

FIGURE 2. Changes of $Z$ scores for BMI-for-age after 6-month nutritional intervention expressed as mean values with $95 \%$ confidence interval.

proved in body height, for 0.32 (95 \% CI: 0.02-0.61, $\mathrm{p}=0.0365)$ in enteral formula and for $0.51(95 \% \mathrm{CI}$ : 0.24-0.79, $\mathrm{p}=0.0005$ ) in pureed food group. Much like weight-for-age Z-scores, BMI-for-age Z-scores increased for 3.75 (95\% CI: $2.41-5.09, \mathrm{p}=0.0000)$ in enteral formula group and for 0.63 (95\% CI: -0.60 $1.87, p=0.3045$ ) in the pureed food group as shown in Figure 2. Z score for BMI-for-age changed significantly in enteral formula group, but not in pureed food group. Both weight-for-age and BMI-for-age $Z$ scores increased significantly more in enteral formula than in pureed food group $(\mathrm{p}=0.0012$ and $\mathrm{p}$ $=0.0014$, respectively).

\section{Changes in body composition}

The percentage of fat increased in both groups of patients, for $6.5 \%$ (95\% CI: $4.5 \%-8.4 \%, \mathrm{p}=0.0000)$ in enteral formula group and for $2.6 \%$ (95\% CI: $0.8 \%-4.5 \%, p=0.0065)$ in pureed food group. The

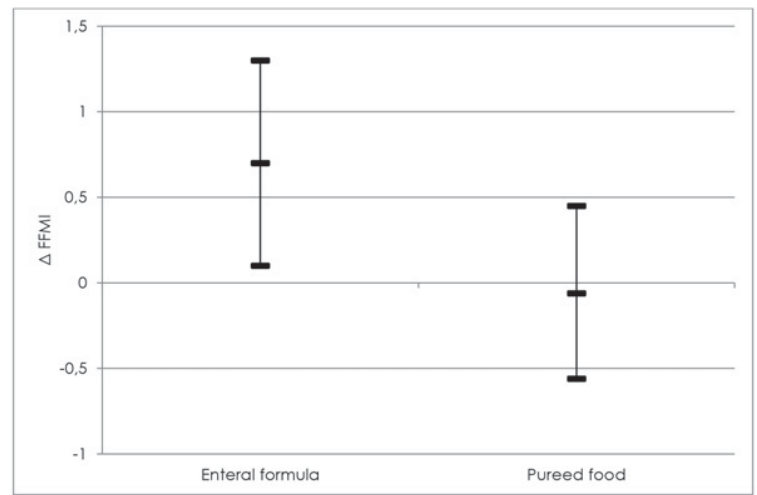

FIGURE 4. Changes in fat-free mass indexes (FFMI) after 6-month nutritional intervention expressed as mean values with $95 \%$ confidence interval. 
increase of $\%$ of body fat was significantly higher in the formula group $(p=0.0051)$. After we converted $\%$ of body fat into body fat mass and lean body mass, we found out increases of both in majority of patients. When normalisation for height was applied with the use of FMI and FFMI, we found significantly higher increase of fat body mass indexes in the enteral formula group than pureed food group (for $1.12 \mathrm{~kg} / \mathrm{m}^{2} ; 95 \% \mathrm{CI}$ : 0.75-1.50; and for $0.38 \mathrm{~kg} / \mathrm{m}^{2}$; 95\% CI: 0.12-0.64; respectively; $\mathrm{p}$ $=0.0012$ ) as presented in Figure 3. According to FFMI, we only found improvement in lean body mass in enteral formula group (for $0.70 \mathrm{~kg} / \mathrm{m}^{2}, 95 \%$ CI: 0.1-1.3) while there was no significant change in pureed food group $\left(-0.06 \mathrm{~kg} / \mathrm{m}^{2}, 95 \% \mathrm{CI}:-0.56-0.45\right)$ $(\mathrm{p}=0.0487)$ which is demonstrated in Figure 4.

\section{Discussion}

To the best of our knowledge, this is the first prospective controlled study that objectively compared efficacy of gastrostomy feeding with professionally designed home-prepared pureed food diet and with commercially available enteral formula for treatment of malnutrition in patients with severe neurological impairment.

Although prescribed energy and nutrient intake were similar for both groups, there was significantly better improvement of both body weight and body composition in the enteral formula group. What is most important, results showed that patients in that group even gained lean body mass, which is extremely difficult to achieve in patients with severe limitations in movement.

Better effectiveness of enteral formula can be explained in different ways. It seems probable that the actual food intake in pureed food group was less than what we had recommended based on calculations of the patient's daily needs. The preparation of fresh food in the quantity and composition corresponding to accurate instructions of a clinical dietitian is a challenging task for parents/carers in comparison to the provision of the recommended daily volume of enteral formulas. We suspect that parents gradually started to improvise, both in the selection of foods and in the amounts (i.e. no more weighting). Even with the same volume of feeding, the daily intake may substantially alter due to a change in the selection of foods and/or their amount (especially the amount of oil or MCT).

Another reason for better effectiveness of enteral formula might also be in slow gastric emptying and gastroesophageal reflux, which are common in patients with severe neurologic impairment. ${ }^{33}$ These patients tolerate poorly large volumes of food. As the energy density of enteral formula (1.5 $\mathrm{kcal} / \mathrm{ml}$ ) is higher than average energy density of pureed food, volumes of pureed food needed to cover energy and nutrient intake were higher. Although parents did not report increase in vomiting or regurgitation, volumes of food prescribed in the intervention were bigger than the ones they were used to before the study for most of the patients.

Furthermore, there is also a chance that biologic availability and utilization of nutrients from enteral formula was significantly better than from pureed food. There were some observational studies in malnourished people in developing countries and animal-model studies that show that both gut and pancreatic structure and function are affected in cases of severe malnutrition. ${ }^{34-36}$ Therefore, digestion and absorption of some of the nutrients could be impaired in our patients. However, enteral formulas used in the study were polymeric enteral formulas based on milk protein. Although manufacturer claimed that their composition of macro and micro nutrient is in ideal proportion and in form with good absorption, there is not much evidence that macronutrients from polymeric formulas are really absorbed better than from natural foods.

Unfortunately, our study had some limitations. The first one is relatively small number of included patients, because the criteria that we used were very strict. Secondly, the randomisation into two groups was not possible due to strict demand of majority of parents for their child to be placed in the group they preferred. That is why the pureed food group patients were significantly younger and therefore less malnourished at the inclusion. It has been well documented that level of malnutrition usually increases with age in patients with severe neurologic impairment. ${ }^{7}$ Although we used multivariate models that take into account the difference in age, more severe undernutrition at the starting point of the study in formula-fed group might affect the results. Metabolic rate of more malnourished patients is lower than the one of less malnourished, because of relatively smaller fat-free body mass, which is the strongest predictor of resting energy expenditure, and adaptation to a chronically low energy intake. ${ }^{37}$ Therefore, with the same energy input, less energy is spend for coverage of basal metabolism and more can be used for growth of body tissues.

Despite aforementioned limitations, the results of this study suggest, that even professionally 
planned diet using pureed food with highly motivated parents/caregivers, who have personally decided to feed their children with home-prepared food, is less effective or at least less reliable in nutritional rehabilitation of malnourished patients with neurologic impairment in comparison to the commercial enteral formula. However, larger and randomised clinical studies comparing efficacy of both feeding regimes should be made in the future to confirm our findings.

\section{Acknowledgements}

We would like to express our sincere gratitude to all the participants and their parents who participated in this study as well as to medical personnel that assisted during the research, especially to Nataša Podlogar, Mojca Kranjc and Jelena Petrošanec.

\section{References}

1. Kuperminc MN, Gottrand F, Samson-Fang J, Arvedson J, Bell K, Craig GM et al. Nutritional management of children with cerebral palsy: a practical guide. Eur J Clin Nutr 2013; 67: 21-3. doi: 10.1038/ejen.2013.227

2. Sullivan, PB, Lambert B, Rose M, Ford-Adams M, Johnson A, Griffiths P. Prevalence and severity of feeding and nutritional problems in children with neurological impairment: Oxford Feeding Study. Dev Med Child Neurol 2000; 42: 674-80. doi: 10.1111/j.1469-8749.2000.tb00678.x

3. Trier E, Thomas AG. Feeding the disabled child. Nutrition 1998; 14: 801-5 doi: 10.1016/S0899-9007(98)00088-4

4. Penagini F, Mameli C, Fabiano V, Brunetti D, Dilillo D, Zuccotti GV. Dietary intakes and nutritional issues in neurologically impaired children. Nutrients 2015; 7: 9400-59. doi: 10.3390/nu7115469

5. Shapiro BK, Green P, Krick J, Allen D, Capute AJ. Growth of severely impaired children: neurological versus nutritional factors. Dev Med Child Neurol 1986; 28: 729-33, doi: 10.1111/j.1469-8749.1986.tb03924.x

6. Fung EB, Samson-Fang L, Stallings VA, Conaway M, Liptak G, Henderson RC, et al. Feeding dysfunction is associated with poor growth and health status in children with cerebral palsy. J Am Diet Assoc 2002; 102: 361-73.

7. Sullivan PB, Juszczak E, Lambert BR, Rose M, Ford-Adams ME, Johnson A. Impact of feeding problems on nutritional intake and growth: Oxford Feeding Study II. Dev Med Child Neurol 2002; 44: 46-67. doi: 10.1111/ j.1469-8749.2002.tb00307.x

8. Samson-Fang L, Bell KL. Assessment of growth and nutrition in children with cerebral palsy. Eur J Clin Nutr 2013; 67: 5-8. doi: 10.1038/ejcn.2013.223

9. Marchand V, Motil KJ; NASPGHAN Committee on Nutrition. Nutrition support for neurologically impaired children: a clinical report of the North American Society for Pediatric Gastroenterology, Hepatology, and Nutrition. J Pediatr Gastroenterol Nutr 2006; 43: 123-35. doi: 10.1097/01. mpg.0000228124.93841.ea

10. Waterman ET, Koltai PJ, Downey JC, Cacace AT. Swallowing disorders in population of children with cerebral palsy. Int J Pediatr Otorhinolaryngol 1992; 24: 63-71. doi: 10.1016/0165-5876(92)90067-Y

11. Benfer KA, Weir KA, Bell KL, Ware RS, Davies PS, Boyd RN. Clinical signs sug gestive of pharyngeal dysphagia in preschool children with cerebral palsy. Res Dev Disabil 2015; 38: 192-201. doi: 10.1016/j.ridd.2014.12.021

12. Morgan AT, Dodrill P, Ward EC. Interventions for oropharyngeal dysphagia in children with neurological impairment. Cochrane Database Syst Rev 2012 10: CD009456. doi: 10.1002/14651858.CD009456.pub2
13. Hirata GC, Santos RS. Rehabilitation of oropharyngeal dysphagia in children with cerebral palsy: A systematic review of the speech therapy approach. Int Arch Otorhinolaryngol 2012; 16: 396-9. doi: 10.7162/S180997772012000300016

14. Martinez-Costa C, Borraz S, Benlloch C, Sanchiz V, Brines J. Early decision of gastrostomy tube insertion in children with severe developmental disability: a current dilemma. J Hum Nutr Diet 2011; 24: 115-21. doi: 10.1111/j.1365277X.2010.01146.x

15. Sullivan PB, Juszczak E, Bachlet AME, Lambert B, Vernon-Roberts A, Grant HW, et al. Gastrostomy tube feeding in children with cerebral palsy: a prospective, longitudinal study. Dev Med Child Neurol 2005; 47: 77-85. doi: 10.1017/S0012162205000162

16. Brant $\mathrm{CQ}$, Stanich $\mathrm{P}$, Ferrari AP Jr. Improvement of children's nutritiona status after enteral feeding by PEG: an interim report. Gastrointest Endosc 1999: 50: $183-8$.

17. Corwin DS, Isaacs JS, Georgeson KE, Bartolucci AA, Cloud HH, Craig CB. Weight and length increases in children after gastrostomy placement. J Am Diet Assoc 1996; 96: 874-9. doi: 10.1016/S0002-8223(96)00239-8

18. Dahlseng MO, Finbråten A-K, Júlíusson PB, Skranes J, Andersen G, Vik T. Feeding problems, growth and nutritional status in children with cerebral palsy. Acta Paediatr 2012; 101: 92-98. doi: 10.1111/j.16512227.2011.02412.x

19. Braegger C, Decsi T, Dias JA, Hartman C, Kolacek S, Koletzko B, et al. Practical approach to paediatric enteral nutrition: a comment by the ESPGHAN committee on nutrition. J Pediatr Gastroenterol Nutr 2010; 51: 110-22. doi: 10.1097/MPG.0b013e3181d336d2

20. Escuro AA. Blenderized tube feeding: suggested guidelines to clinicians. Pract Gastroenterol 2014; 138: 58-66.

21. Sullivan MM, Sorreda-Esguerra P, Platon MB, Castro CG, Chou NR, Shott $S$, et al. Nutritional analysis of blenderized enteral diets in the Philippines. Asia Pac J Clin Nutr 2004; 13: 385-90.

22. Jalali M, Sabzghbaee MM, Badri SS, Soltani HA, Maracy MR. Bacterial contamination of hospital-prepared tube feeding formulas in Isfahan, Iran. J Res Med Sci 2009. 14: 149-56.

23. Borghi R, Araujo TD, Viera RIA, de Souza TT, Waitzberg DL. ILSI task force on enteral nutrition: estimated composition and costs of blenderized diets. Nutr Hosp 2013; 28: 2033-8. doi: 10.3305/nutr hosp.v28in06.6759

24. Hurt RT, Edakkanambeth Varayil J, Epp LM, Pattinson AK, Lammert LM, Lintz JE, et al. Blenderized tube feeding use in adult home enteral nutrition patients: A cross-sectional study. Nutr Clin Pract 2015; 30: 824-9. doi: $10.1177 / 0884533615591602$

25. Edwards S, Davis AM, Bruce A, Mousa H, Lyman B, Cocjin J, et al. Caring for tube-fed children: A review of management, tube weaning, and emotional considerations. J Parenter Enteral Nutr 2016; 40: 616-22. doi: $10.1177 / 0148607115577449$

26. WHO AnthroPlus for personal computers Manual: for assessing growth of the world's children and adolescents. Geneva: WHO; 2009. Available at http://www.who.int/growthref/tools/en/

27. Deutsche Gesellschaft für Ernährung, Österreichische Gesellschaft für Ernährung, Schweizerische Gesellschaft für Ernährungsforschung, Schweizerische Vereinigung für Ernährung. [Reference levels for nutrient intake]. [German]. Neustadt: Neuer Umschau Buchverlag; 2008.

28. Bell KL, Samson-Fang L. Nutritional management of children with cerebral palsy. Eur J Clin Nutr 2013; 67: 13-6. doi: 10.1038/ejen.2013.225

29. Gauld LM1, Kappers J, Carlin JB, Robertson CF. Height prediction from ulna length. Dev Med Child Neurol 2004; 46: 475-80. doi: 10.1111/j.14698749.2004 .tb00508x

30. Slaughter MH, Lohman TG, Boileau RA, Horswill CA, Stillman RJ, Van Loan $\mathrm{MD}$, Bemben DA. Skinfold equations for estimation of body fatness in children and youth. Hum Biol 1988; 60: 709-23.

31. Gurka MJ, Kuperminc MN, Busby MG, Bennis JA, Grossberg RI, Houlihan $\mathrm{CM}$, et al. Assessment and correction of skinfold thickness equations in estimating body fat in children with cerebral palsy. Dev Med Child Neurol 2010; 52: 35-41. doi: 10.1111/j.1469-8749.2009.03474.x

32. R Development Core Team. R: A language and environment for statistical computing. Vienna: R Foundation for Statistical Computing; 2009. ISBN 3-900051-07-0. Available at http://www.R-project.org 
33. Sullivan PB. Gastrointestinal disorders in children with neurodevelopmental disabilities. Dev Disabil Res Rev 2008; 14: 128-36. doi: 10.1002/ddrr.18

34. Durie PR, Moore DJ, Forstner GG. Malnutrition and the exocrine pancreas. In: Walker-Smith JA, McNeish AS, editors. Diarrhoea and malnutrition in childhood. London: Butterworth \& Co. Publishers Ltd; 1986. p. 135-46.

35. Hamilton R. The effect of malnutrition on gut structure, function and healing after injury. In: Walker-Smith JA, McNeish AS, editors. Diarrhoea and malnutrition in childhood. London: Butterworth \& Co. Publishers Ltd; 1986. p. 23-7.

36. Penny ME. Protein-energy malnutrition: patophisiology, clinical consequences, and treatment. In: Duggan C, Watkins JB, Walker WA, editors. Nutrition in paediatrics. Hamilton: BC Decker Inc; 2008. p. 127-41.

37. Arrowsmith FE, Allen JR, Gaskin K, Sommerville H, Birdsall J, Barzi $F_{\text {, }}$ O'Laughlin EV. Nutritional rehabilitation increases resting energy expenditure of malnourished children with severe cerebral palsy. Dev Med Child Neurol 2012; 54: 170-5. doi: 10.1111/j.1469-8749.2011.04166.x 